\title{
Limits to the implementation of benchmarking through KPIs in UK construction policy: insights from game theory
}

John Rigby, Paul Dewick, Roger Courtney, Sally Gee

This is an Author's Original Manuscript of an article published by Taylor \& Francis in Public Management Review on $21^{\text {st }}$ January 2013 available online at http://www.tandfonline.com/[ http://dx.doi.org/10.1080/14719037.2012.757351]

\begin{abstract}
Benchmarking through the use of key performance indicators (KPIs) has been an important part of the UK government's market-oriented reforms to improve efficiency across the public sector and in other areas such as construction where government is a major client. However, government attempts to implement construction KPIs have not followed the expected course. We argue that insights from game theory show that the initial plan for construction benchmarking failed to take account of the strategic value of the information collected and was not implementable because the sharing of information by construction suppliers with their clients was a dominated strategy.
\end{abstract}

New Keywords procurement

\section{Introduction}

This paper presents an analysis of the development of the UK government's policy for construction key performance indicators. It sets out the rationales used by government for intervention in construction policy and then explains how the rise of the new public management during the 1990s gave impetus to an ambitious approach to benchmarking that involved exchange of information between both the industry and the industry's clients. As our review of the benchmarking and game theory literatures makes clear, benchmarking creates information with strategic value. In policies to promote benchmarking with key performance indicators (KPIs), account must be taken of the strategic value of information. Indeed, we suggest that the development of a benchmarking policy involving different groups of actors each with a common interest is best represented as a two person pay-off matrix. We further 
suggest that no benchmarking and KPI policy with negative payoffs for either or one of the participants is likely to emerge without compulsion. Our UK case study, informed by both secondary review and primary data analysis, shows the attempt was made to introduce industry and client benchmarking in the construction context on a voluntary basis, but the development of the policy did not then take the course that was originally proposed because benchmarking had negative pay offs for construction suppliers whose choice to exchange information with clients was a dominated strategy. What emerged was a policy for benchmarking that did not involve the flow of strategic information from suppliers to clients. It is suggested that the use of a game theoretic approach to policy development and implementation is essential to understanding the limits to the design of policies.

\section{Literature Review}

\section{Government intervention in construction policy}

In the UK, government has had a long standing interest in the performance of the construction industry and commitment to the improvement of its performance. The longevity of the output of construction, the significant proportion of construction output bought by the public sector, concerns about the capabilities of the industry and its low level of client satisfaction have led successive governments to support the industry through a standards and advice regime, grounded in research, and organized by an advisory body of specialists employed by a purposely created research organisation. The earliest manifestation of a governmental commitment to address this concern came with the creation, in 1921, of the Building Research Station or BRS (Courtney, 1997). The BRS, later the Building Research Establishment (BRE), became the government's and industry's key research body. Even after the publication of the Rothschild Report in 1971 (Cmd. 4514, 1971), which required relationships between government and organisations relying on public money for support as BRE did to take on a more commercial form, the industry still received significant help from government. The manner in which government provided assistance to industry continued in a very similar way from around 1920 until in 1997 when privatization of the BRE took place. This change marked an end to an emphasis upon direct assistance 
for research and development and the start of a new approach based on provision of information and advice.

\section{Economic Rationales for Policy}

The approach to government intervention in the economy emerging during the $1980 \mathrm{~s}$ was justified by reference to what neoclassical economic theory describes as market failures (HM Treasury, 2003) ${ }^{1}$. The UK Government in common with other developed world governments justifies its intervention in the economy by the need to alleviate such failures. In the context of markets for construction products and services (as in many markets), two market failures are held to occur for the following reasons. Firstly, in the research and development and innovation process $(R, D \& I)$ there are positive externalities (public goods aspects of learning). This leads to an overall underinvestment that justifies government intervention to support the level of investment in $\mathrm{R}, \mathrm{D}$ \& I and to promote dissemination. Secondly, variety and novelty in products and processes offered increases the risk products or processes will not work as expected. Differential information about the performance of goods and services offered by suppliers and the specific needs of procurement organisations of clients (information asymmetries) then leads to adverse selection and moral hazard, both of which reduce market actors' ability to transact efficiently. This in turn lowers the level of economic activity.

Central to both of the approaches to remedy these market failures is information. In the first, government can support the process of research development and innovation by financial support and, in order to disseminate the resulting knowledge, government should also support information dissemination. In the second, information asymmetries can be remedied by action that aims to secure agreement on standards of performance of products and services, thereby giving confidence to users and suppliers. While learning effects that correct market failures undoubtedly occur, for

\footnotetext{
${ }^{1}$ In the UK, the Government's Green Book (HM Treasury, 2003) identifies the rationales upon which its economic policies for market failure are based. The Green Book gives four sets of conditions under which market failure arises: a) public goods; b) externalities; c) imperfect information; d) market power.
} 
example when firms learn from others in the same industry (von Hippel, 1988), and from their clients through user driven innovation and from firms in other industries (Allen, 1983), market failures often persist and are systemic issues that must be addressed through concerted intervention. We now consider the suitability of a key business information process for performance improvement, benchmarking through the use of key performance indicators, as a tool with which to address the market failures present in the market for construction products and services.

\section{Benchmarking with KPIs: an information strategy}

A number of typologies of benchmarking have been offered (Dattakumar and Jagadeesh, 2003). One of the best known, which is attributed to Camp (Camp, 1995), and which appears in a number of practitioner-oriented texts, e.g. (Anderson and Peterson, 1996) describes an information management activity with two main aspects: the nature of the comparison being made (the benchmark or indicator), and the scope of the actors involved. Camp's analysis distinguishes three main levels at which benchmarking takes place, performance benchmarking, process benchmarking and strategic benchmarking. It also views these activities as involving four different sets of actors: a) within the firm - so-called internal benchmarking where the benchmarking is only within an economic unit; b) competitor benchmarking where comparisons are made between firms by each other but without any agreement; c) functional benchmarking where comparisons are made across a whole industry in a systematic manner; and d) generic benchmarking where comparisons are made by actors in different industries.

Benchmarking is an information based approach to performance management, widely used in the business sector, and capable of application in many different settings. It has an key role in the activities to support total quality management (Anderson and Peterson, 1996). Its continued prominence reflects its central importance to the productive activity of firms according to Francis and Holloway (2007). Its application by the Xerox Company, see Zairi, (1998), is generally regarded as proof of its potentially transforming effect upon organizational performance. As a demonstrated tool of 
information management and measurement, benchmarking appears to be a suitable methodology by which to disseminate information to help learning by other firms in an industry, and to those involved in procurement to choose the best supplier.

The critical benchmarking literature nevertheless draws attention to difficulties of implementing a benchmarking activity successfully, and some inherent problems of benchmarking stemming from the strategic value of the information collected. Cox and Thompson (1988) note that benchmarking requires considerable care in application as the information collected may not be relevant, or what is collected may not always be correctly applied. Other commentators in the benchmarking literature also emphasize the importance of information flows within a benchmarking system in terms of who sees the information and can use it (Boxwell (1994), Wolfram Cox et al (1997)). Boxwell's contribution (1994) focused on the issue of information exchange, showing that in competitive benchmarking, information flows in one direction only; whereas in collaborative benchmarking, information flows in both directions with each party having a chance to learn from others.

Importantly, a small number of commentators have noted that the flow of information in benchmarking is inherently problematic because information has value. Murnighan (1994), following Spendolini (1992), has suggested that the behaviour of those engaged in benchmarking cannot be fully understood without reference to game theoretic perspectives as these address the strategic value of information possession and exchange. We now turn to work which has examined the widespread uptake of benchmarking through key performance indicators in the public sector within so-called performance regimes.

\section{Performance monitoring by the client - the NPM}

Beginning in the 1980s, developed-world governments began to adopt the "New Public Management" approach to their respective public sector organisations, in addition to their increasing use of the neoclassical framework's market failure concept to justify 
(often in the sense of limiting) their intervention in the economy. The New Public Management (NPM) was an approach that spread widely around the world and represented a major break with the past (Hood, 1991). Such reforming measures claim their authority from private sector models of efficiency and competition. The use of benchmarking with key performance indicators became a key feature of the NPM. And while benchmarking was widely applied in the public sector, it was also applied to private organisations responsible either for delivering key public services or services sold to the public sector (Talbot, 2010 page 171).

Benchmarking and key performance indicators constitute one aspect of the measurement systems or "performance regimes" that develop within the complex environment of key actors, including government, the legislature, in fact any actor that has institutional power. Talbot has recently offered an analysis of the processes by which intervention and control frameworks are influenced, shaped and developed to become "performance regimes". The theories of performance perspective suggests that benchmarking can support all the major forms of intervention to varying degrees by generating the information needed for the following main dimensions of the performance regime: a) informing decisions taken by managers and helping them allocate resource between competing purposes or organisations; b) providing signals in quasi-market conditions; c) informing users of a service of levels of quality; and d) locating activities where improvement can be made by enhancing capability (Talbot, 2010, page 103).

Thus, both from within the neoclassical frame of reference and within the new approach to the management of public organizations and public services (where they might be operated by private organisations) the use of information plays a key role in disseminating good practice (knowledge of what works) and helping clients identify the best supplier to carry out work. However, in the development of the performance regime for construction, the key influencing factors were actors' understandings of the strategic value of the information, and the voluntary nature of the regime in which the participants were to participate. 
Given a government commitment to benchmarking to raise private sector performance levels and the government's general requirement to intervene in the economy by addressing market failures, we now consider how a policy to improve the performance of the construction industry and increase the satisfaction of clients can be implemented. An understanding of the limits to what can be achieved with benchmarking policy will come from considering game theory and the insights about the strategic value of information noted by two important writers on benchmarking (Murnighan, 1994, Spendolini, 1992).

\section{Options for the Design of a Benchmarking Policy}

The purposes of a benchmarking policy or regime for a particular sector such as construction are to address market failures caused by public goods aspects of learning and by information asymmetries. This requires the provision of information that helps firms learn about the most effective ways of providing the products and services they offer; and a means of giving clients information allowing them to determine which suppliers would be the most suitable to carry out particular work.

The use of information by construction firms and clients can take two general forms depending upon the way information is used. In dealing with the market failures associated with research and development, government can help firms learn from each other by disseminating information between them about best practice. This is referred to as 'first order' benchmarking. But benchmarks can also be used to allow procurement organisations or clients to assess the performance of construction firms. Here information can be accumulated either by clients solely, based on their experiences or it can be requested from suppliers to help clients draw a detailed picture of their suppliers' performance. This information can then be further shared amongst clients, giving them a powerful tool to compare construction firms against each other. This sharing of information between different types can be termed 'second order'. The combination of first order and second order benchmarking relates strongly to Camp's (1995) notion of 'functional benchmarking' referred to earlier. 
Given the evident effectiveness of benchmarking in supporting innovation amongst firms on the one hand, and dealing with market failures of information that exist for clients on the other, the case for government combining such policies into a single programme or scheme appears a sensible use of resources. However, as we show in the next section, the implementation of a combined programme with information widely shared between suppliers and clients is not straightforward.

\section{Benchmarking: insights from game theory}

The application of game theory methods to study actors within a variety of contexts, including policy contexts, is an important and expanding research area, particularly where institutions, including government are involved. O'Toole (2004) called for researchers in policy implementation to recognize the importance of interaction between actors for successful policy implementation, and the use of game theory to understand the choices available to policy actors - and thereby the means by which successful implementation of policy can be accomplished - has since been undertaken by a variety of scholars (Frisvold and Caswell, 2000) (Eleftheriadou and Mylopoulos, 2008).

One of the best known examples of the use of game theory in policy making is the auction of the UK Radio Spectrum (Binmore and Klemperer, 2002). The contribution made by game theoretic approaches to the design of policy - so-called "mechanism design", whereby sustainable, albeit second best, solutions to economic and social problems (Binmore, 2007) can be sought - has in fact been developing for around three decades. The study of how to implement policy within the game theoretic paradigm of mathematically based economics and political science parallels the concern of implementation studies within the context of the field of public administration. While game theory explanations seek to identify strategy and outcomes based on payoff systems, implementation theory seeks to find answers to the question of how games themselves should be designed (Jackson, 2001). Commonly, the approach in the context of economic mechanism design is to start with 
an assumption of how the game should end and then to work towards establishing rules by which those involved in the mechanism should be permitted to act.

Of equal significance is the contribution game theory has made to the consideration of policy implementation, both to develop policy responses to existing dilemmas or to implement policy in wholly new areas. Implementation theory in the context of auctions is one such relatively new application of the game theoretic approach and it has yielded some significant results. However, to date, little has been done in the construction policy context apart from Eriksson's work applying game theory illustratively to contracting practices, his aim being to elucidate the link between the duration of contracting relationship (between client and supplier) and the expectations of payoffs (Erikson, 2007).

In the context of construction benchmarking, the two main actors which government encourages to interact are suppliers and procurement organisations/clients. Their representatives participate in the actual development of a policy and must choose between various policy options on the basis of their assessment of the value of the potential outcomes of the policy. There are a large number of ways in which benchmarking schemes can be implemented. At one extreme, benchmarking may be internal to the firm with no information exchanged. At the other extreme, all client and supplier information is available to all other parties. For example, where all information is available, what could be called a completely open scheme, each supplier's information is available to every other supplier and to each and every client, there is no anonymisation of data, and data are available at individual firm level and can be analysed at any level and any form of comparison is possible. Where, however, government has determined certain aims for the scheme, i.e. using benchmarking to increase the supply of public goods on the one hand and to remove information asymmetries in the market for construction services on the other, the main rules of the game are defined. It is then for the players, who are the representatives of the groups, to consider the payoffs for those they represent and then to determine their respective strategies. 
We present in the following figure, Figure 1, the options and outcomes for suppliers and clients. Suppliers have the option over the extent to which they are willing to collaborate in intra-group - so called, first order - benchmarking schemes (i.e. sharing information within supplier groups) and inter-group - so called, second order benchmarking schemes (i.e. sharing information between supplier groups and client groups). Client groups have the option over the extent to which they are willing to collaborate in the second order benchmarking scheme (they are not involved in the first order scheme). The extent of supplier group and client group willingness to collaborate has been classified as low or high.

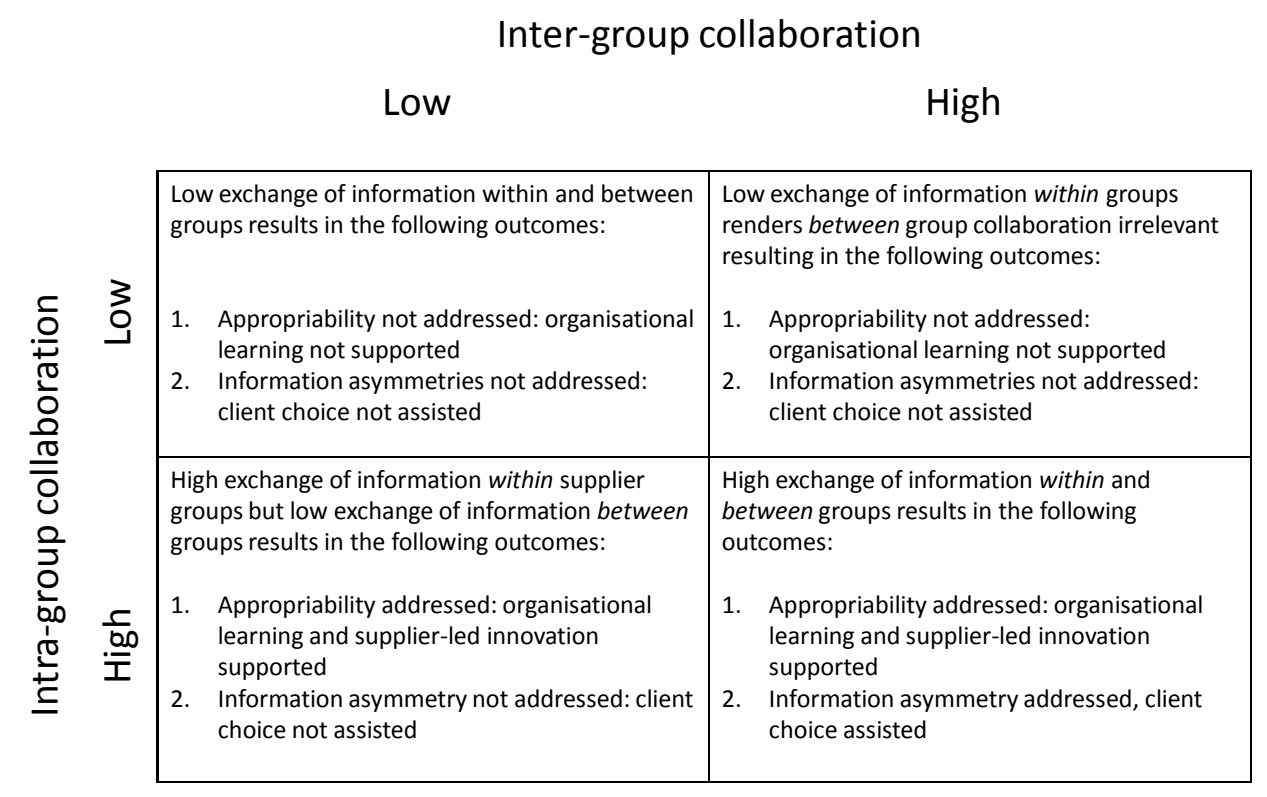

Figure 1 Benchmarking Options Matrix

When collaboration is low, there is low engagement (of either suppliers or clients or both) and/or data is restricted (e.g. anonymised, available at an aggregated level, available only to certain groups). When collaboration is high, it means that there is high engagement (e.g. supplier's information is available to all other construction firms and to each and every client) and/or that the data is unrestricted (e.g. full data available at individual level and any form of comparison is possible). 
The strategy choice that corresponds to the twin policy aims of supporting public goods by disseminating learning outcomes and providing clients with information about construction firms is the bottom right box where there needs to be a willingness to collaborate within and between groups. The bottom left box, where willingness to collaborate within groups is high, enables intra-supplier group benchmarking and could benefit construction firms in terms of organisational learning, meeting the objectives of the public goods policy. But it will not address the information asymmetries policy aim. The top left-hand and right-hand boxes lead to similar outcomes because if the suppliers' willingness to collaborate in second order benchmarking schemes is low, the willingness of client groups to collaborate is irrelevant. In this case, neither policy aim is met sufficiently.

\section{Research method}

Between December 2007 and April 2008, as part of a review² of construction KPIs for the Department of Business, Enterprise and Regulatory Reform and with the assistance of Constructing Excellence and members of the KPI consortium, we conducted 32 interviews with current or previous users of the KPIs from 30 organisations. Interviews

\footnotetext{
${ }^{2}$ The Review was commissioned by BERR to inform decisions over future Government support for the production of the KPIs. Courtney et al (2008) contains sensitive financial information and is not publically available but an Executive Summary of the Review can be accessed at http://www.bis.gov.uk/analysis/statistics/construction-statistics/key-performance-indicators. Its objectives were to:

- Examine whether the construction KPIs meet the objectives set for them, and the benefits derived from their publication.

- Assess the extent and distribution of the resource inputs required to produce them.

- Examine the case for their continuation, and for future government support, and presenting these in a Business Case for the KPIs.

- Provide an account of the present arrangements and an inventory of outputs.

- Make recommendations for changes in the content of construction KPIs and the processes involved in data collection and construction KPI preparation.
} 
were conducted by telephone and lasted between 30 minutes and one hour; a list of interviewees can be seen in Table 1 below.

Table 1 List of Interviewees

\begin{tabular}{|l|l|}
\hline Job Title & Affiliation \\
\hline Assistant Director of Construction & Peabody Trust \\
\hline Partner & Sheppard Robson \\
\hline Chairman & Radway Door and Windows Ltd \\
\hline Director & HTA Architects \\
\hline Business Process Manager & Marshalls \\
\hline $\begin{array}{l}\text { Head of Employment, Skills and } \\
\text { Performance Management }\end{array}$ & Olympic Delivery Authority \\
\hline Deputy Director of Estates & The University of Manchester \\
\hline Business Development Manager & John Laing Partnership \\
\hline $\begin{array}{l}\text { Head of Development, Strategy and } \\
\text { Policy }\end{array}$ & Circle Anglia \\
\hline $\begin{array}{l}\text { Corporate Development Team Manager } \\
\text { (Innovation, KPIs and Continuous } \\
\text { Improvement) }\end{array}$ & MITIE Engineering Services \\
\hline Central Management Systems & Laing O'Rourke Group \\
\hline Performance Improvement Director & Carillion Construction Ltd \\
\hline Capital Programme Director & Manchester City Council \\
\hline Customer Care Manager & Lorne Stewart \\
\hline Deputy Director of Projects & Defence Estates \\
\hline Partner & MEPK Architects \\
\hline Director of Estates & University of Essex \\
\hline Executive Board Member & Taylor Wimpey \\
\hline Business Improvement Director & \\
\hline Project Leader Knowledge Management & Nailey \\
\hline
\end{tabular}




\begin{tabular}{|l|l|}
\hline Partner & Drivers Jonas \\
\hline Performance Integrator & Fusion 21 \\
\hline Director and Equity Partner & Turner and Townsend \\
\hline $\begin{array}{l}\text { Partnering Manager and Performance } \\
\text { Management }\end{array}$ & Lovell Partnerships Ltd \\
\hline National Accounts Director & Sheffield Insulation Group \\
\hline Project Operations Director & Centre for Construction Innovation \\
\hline $\begin{array}{l}\text { Strategic Development and Business } \\
\text { Improvement Director }\end{array}$ & Land Securities \\
\hline General Manager & Birmingham City Council Ltd \\
\hline Design Unit Service Manager & The University of Manchester \\
\hline New Business Manager & McCann Homes Limited \\
\hline Capital Project Director for R\&D Group & GSK \\
\hline
\end{tabular}

With relevance to the case study we explore in this paper, interview questions probed industry (supply side and client) use of construction KPIs and the perceived benefits of doing so $^{3}$. In parallel to the interviews, we held discussions with representatives of BERR and the Office of Government Commerce (OGC), as a principal stakeholder in the construction sector, to gain their views of the construction KPIs. These enquiries were supplemented by examination of KPIzone, the KPI Website (www.KPIzone.com), where we were provided with complimentary access to the Members' area of the site. In addition, we conducted extended discussions and follow-up enquiries with the principal members of the 'KPI Consortium' (i.e. the set of bodies included in the contract for the preparation of the KPIs) and with Constructing Excellence which at that the time of the contract was in receipt of separate Government funding but which now funds the publication and promotion of the KPIs from its own resources. To this

\footnotetext{
${ }^{3}$ For example, we asked "Which sets of construction KPIs has your organisation used, and how have they been used?" "What actions have been taken which have been stimulated or influenced by the construction KPIs?" "Will you continue to use the construction KPIs?" "Can you see your use of construction KPIs increasing or changing in other ways?"
} 
end, eight interviews were also held with representatives of BPA Consult and Amazia Ltd, BRE Ltd, Building Services Research and Information Association, Construction Products Association and Constructing Excellence.

In addition, to provide opportunity for a wider range of inputs to the Review, we also prepared an on-line questionnaire, covering similar issues to the interviews. This was operational from 1st February 2008 to 10th April 2008. Members of the KPI Consortium assisted the Review by promoting (twice) the questionnaire to their various constituencies and it was further promoted by the Review Team using their contacts. The questionnaire respondents were not (and were not expected to be) representative of construction generally, but provided a wider set of perspectives on the construction KPIs. 129 usable responses were received to the questionnaire. Although not reported here, the views expressed in the responses aligned well with those obtained from the interviews in that they showed positive views on the construction $\mathrm{KPIs}^{4}$.

Drawing on contemporary government reports and analysis of interviews with construction KPI users, the next section explores how the policy for improvement based on benchmarking of the performance of construction firms and use of benchmark data by construction firms and by clients was designed and implemented, and then what the ultimate outcome of the process of implementation was.

\section{The Evolution of UK Construction Benchmarking Policy}

\section{Design and Implementation}

The UK construction industry key performance indicators were originally proposed to meet both construction firm and client objectives and to do so with overlapping

\footnotetext{
${ }^{4}$ The questionnaire provided additional information on some aspects of the promotion and use of construction KPIs (e.g. on the ways in which respondents had heard about the construction KPIs, the sets that are mainly used in supplier selection and the additional information used by construction KPI users when deciding to take improvement actions).
} 
information collecting and analysis processes. There was considerable political support for the development of an integrated process that united benchmarking for the use of clients and construction firms. The process appeared a prima facie means to achieve government policies of supporting innovation and development amongst construction firms and to reduce information asymmetries in the market place for construction services with the intention of addressing the industry's perceived problems of high cost/poor performance and client dissatisfaction. The use of benchmarking and information was highlighted in the 1994 Latham report, 'Constructing the Team', and later stressed in the 1998 Egan report 'Rethinking Construction' (Egan, 1998, Latham, 1994). The development began in favourable circumstances with relative political stability, strong political will, significant policy time to devote to the project, and support from within the industry itself and from clients.

The Latham Report (1994) proposed major changes to the regulation of the industry, including the creation of the Construction Industry Board, a significant new entity which had an important role in developing of indicators with which to monitor progress. In the early stages, the Board expected that the target of the report, of a $30 \%$ reduction in the real costs of construction, could be achieved by 2000 . The focus at this stage was upon supplier benchmarking. Progress using the indicators did not take place as quickly as originally hoped. The Construction Task Force, established by the Deputy Prime Minister, John Prescott, argued for major changes and implied a strong link between the performance of the industry and the satisfaction levels of its clientele: "the construction industry is under-achieving, both in terms of meeting its own needs and those of its clients." (Egan, 1998 ; page 6). The argument that client expectations should be used to leverage improvement in the performance of the sector grew in force: "Our experience tells us that ambitious targets and effective measurement of performance are essential to deliver improvement. We have proposed a series of targets for annual improvement and we would like to see more extensive use of performance data by the industry to inform its clients", thereby giving clients the ability to "recognize increased value and reward companies that deliver it" (Egan, 1998; page 14). Egan proposed an industry wide scheme that would be of great benefit to 
clients in which information would be used to drive up standards. Paragraph 21 of the report announced:

'Construction must put into place a means of measuring progress towards its objectives and targets. The industry starts with a clean sheet in this respect. It has a great opportunity to create an industry-wide performance measurement system which will enable clients to differentiate between the best and the rest providing a rational basis for selection and to reward excellence.'

The Egan Report therefore saw performance indicators not only as means of monitoring the industry's progress towards overall performance targets, but also as a tool to assist clients in their procurement decisions. The report underlined the importance of leverage, noting that:

'In addition to objectives and targets, the Task Force would like to see:

The construction industry produce its own structure of objective performance measures agreed with clients; construction companies prepare comparative performance data and share it with clients and each other; $a$ system of independently monitored company 'scorecards', measuring companies' progress towards objectives and targets, instead of simple benchmarking. The names of the best performers would be made public and every company would be privately informed of where it stood in relation to its competitors.'

The report therefore foresaw a managed system not beholden to any interest group and operating with such a degree of thoroughness that the veracity of its data would not be open to challenge. While the system did not at this stage promise league tables of the best performing construction firms, it is clear that what was proposed would, almost certainly lead to their creation. 
Following the publication of the Egan Report, a joint industry/government initiative created the KPI Working Group in 1998 to develop appropriate indicators, monitor progress and make recommendations. While the Group emphasized that construction firms would use benchmarks to improve performance "to identify strengths and weaknesses, and assess their ability to improve over time", the Group also foresaw that benchmarks would be central to the procurement decisions of clients: "Clients, for instance, assess the suitability of potential suppliers for a project, by asking them to provide information about how they perform against a range of indicators. Some information will also be available through the industry's benchmarking initiatives, so clients can see how potential suppliers compare with the rest of the industry in a number of different areas". Ultimately the Group decided in favour of a 'scorecards' based approach. These became an internal rather than external monitoring tool (KPI Working Group, 2000) ${ }^{5}$. Additionally, an EFQM (Business) Excellence Model was proposed as "the most effective tool for analysing all aspects of an organisation's operations" (KPI Working Group, 2000 ; page 8).

The development of the construction KPIs provided an important window through which other actors in government and in Parliament reviewed the progress being made by the construction industry. In 2001 The National Audit Office (NAO) reviewed the government's initiatives to improve construction, producing a report, 'Modernising Construction', which dealt with the effect upon the public sector of poor supplier performance (National Audit Office, 2001). However, if there had been some expectation that the government itself would promote the use of indicators that measured construction firms across the public sector, the conclusions of Modernising Construction indicated that practice fell short of the ideal. Page 49 of the report noted that:

\footnotetext{
${ }^{5}$ The KPI Working Group (2000) report expanded on the targets and KPIs of the Egan (1998) report by identifying three categories of construction KPIs: 1) "Headline" ('measures of the overall, rude state of a health of a firm'); 2) "Operational" ('specific aspects of a firms' activities which should enable management to identify and focus upon specific areas for improvement'); and 3) "Diagnostic" ('information on why certain changes may have occurred in the headline of operational indicators ....useful in analysing areas of improvement in more detail'). The original (2000) construction KPIs as defined by the KPI Working Group can be seen in the Appendix.
} 
"The Government Construction Clients Panel and the Office of Government Commerce have developed a series of six input and 12 output key performance indicators to measure performance during the life of the project. A software system for collating and analysing the data is being piloted. The system will be rolled out across central government in early 2001."

At this early stage, therefore, the Office of Government Commerce (OGC) were developing their own indicators and they have continued to operate a separate performance monitoring system for government projects, although with exchange of data with the construction KPIs.

The NAO commented (page 49) that:

"The Key Performance Indicators have been particularly useful to organisations with unsophisticated performance measurement systems. Some companies have used the indicators selectively to measure aspects which are important to their business and to the clients, and have used them to supplement their own performance measurement systems. The Key Performance Indicators are not a substitute for more comprehensive performance measurement systems and benchmarking, which can provide more reliable assessments...The indicators are less suitable as tools to manage projects, suppliers or companies or as criteria for evaluating tenders or in evaluating the success of construction project in reducing the operational costs of a building. The Department of the Environment, Transport and the Regions recognises that more needs to be done to develop objective and comprehensive measures to demonstrate construction performance, and in particular to promote further improvements by both departments as clients and construction firms."

The NAO recommendations further noted that whilst the construction KPIs were an important first step, the industry should create more detailed and sophisticated 
measures. When the achievements of Rethinking Construction were examined in 2002 by the Strategic Forum, their report paid relatively little attention to the construction KPIs (Egan, 2002). The report focused on what evidence the construction KPIs provided - i.e. their use as a general policy tool - noting that, as a result of their creation it could be said that the Movement for Innovation and Housing Forum demonstration projects were better than the industry average, and that data from 2001 construction KPIs showed the first evidence of an improvement in overall industry performance.

As the construction KPIs took shape following the KPI Working Group report, development occurred in two main directions, neither of which involved clients to the degree originally envisaged. By the time of our Review, the number of areas covered by the construction KPIs had increased significantly to include additional 'Economic' indicators and, following the Respect for People Task Group (Constructing Excellence, 2004) and the Sustainable Construction Task Group (Department of Trade and Industry (DTI), 2004), the introduction of 'Respect for People' and 'Environmental' indicators'. Indeed, the objectives of the construction KPIs were by now quite different from those originally proposed, with three main aspects: a) to provide a method for organisations to benchmark their own performance; b) to provide a means for assessing innovative projects, for example those carried out in the Rethinking Construction Demonstration projects against the rest of industry; $c$ ) a general barometer by which industry progress at a general level could be assessed against the Rethinking Construction targets ${ }^{7}$. Thus,

\footnotetext{
${ }^{6}$ See Appendix for the full list of 2007 'Economic', 'Respect for People', and 'Environment' construction Key Performance Indicators for 'All Construction'. See also Constructing Excellence (2010) for a narrative about the changing performance of the construction industry as measured by the KPIs between 2000 and 2010.

${ }^{7}$ Compare these objectives with those of the original set of KPIs published in January 2000. The KPI Working Group (2000) stated:

1) 'The purpose of the KPIs is to enable measurement of project and organisation performance throughout the construction industry. This information can then be used for benchmarking purposes, and will be a key component of any organisation's move towards achieving best practice.

2) Clients, for instance, assess the suitability of potential suppliers for a project, by asking them to provide information about how they perform against a range of indicators. [Italics added.] Some information will also be available through the industry's benchmarking initiatives, so clients can see how potential suppliers compare with the rest of the industry in a number of different areas.
} 
the construction KPIs as used in 2002 had lost any specific link to procurement. At the time of our interviews with construction KPI users, the statement of the purpose of the construction KPIs emphasised benchmarking for construction firms (KPI Zone User Manual, 2007), and while the User Manual did include reference to the use of the construction KPIs to provide support for procurement decisions, there was no longer any notion of a systematic attempt to integrate benchmarking by construction firms with the needs of clients.

\section{Outcomes}

Our interviews with users emphasised that construction KPIs provided a suitable basis for performance monitoring within the organisation (..."what gets measured, and reviewed and acted on gets done...", was a familiar refrain) and focused attention on targeted improvements; not just strategic, long-term targets but also day-to-day targets. At the strategic level, for example, the use of construction KPIs promoted the adoption of new internal procedures and led to changes in the culture of companies, contributed to the identification of recruitment and retention needs and prompted greater involvement with external agencies (e.g. Waste and Resources Action Programme (WRAP) and BRE for environmental issues). At the operational (day-to-day) level, construction KPIs helped to identify actual or potential ("bubbling underneath") problems in existing projects or relationships.

There was evidence also that internal benchmarking using the construction KPIs had led directly to improvement actions within the organisation. According to those interviewed, the information provided through construction KPIs assisted in the identification of problems and development of remedial or improvement actions, providing focus, legitimacy and transparency in business improvement measures. Examples of outcomes quoted by a main contractor included improvements in quality ( $77 \%$ reduction in defects on some sites) and cost (new housing costs down by $15 \%$ ), higher performance from the supply chain, an accident rate below the industry

3) Construction supply chain companies will be able to benchmark their performance to enable them to identify strengths and weaknesses, and assess their ability to improve over time.' 
average, productivity improvements of up to $40 \%$, an average client satisfaction score in excess of $90 \%$ and a reduction in construction times of up to $30 \%$.

However, whilst our interviews provided some evidence to support the contribution of construction KPIs to internal benchmarking, there was far less unanimity on their use for first order (inter-construction firm) comparisons. Some interviewees argued that an important aspect of the use of construction KPIs was as a benchmarking tool: for example, one mechanical and electrical contractor reported that the construction KPIs had revealed a problem with their productivity when compared with the national average, which had led the organisation to participate in a DTI/Constructing Excellence project (CLIP - Construction Lean Implementation Programme) and to develop its own in-house productivity improvement programme. Another interviewee reported that by demonstrating high performance by comparison with national distributions in work undertaken for a city council, they had gained further public sector projects. However, the majority of interviewees had misgivings about the comparability of construction KPI benchmarking data; in particular they were concerned that the national distributions were inaccurate. One contractor stated that “We don't use [construction] KPIs for national benchmarking as this is pointless - organisations do not collect their data in the same way - we only benchmark to contractors that we regard as immediate peers as we know the data are collected in the same way". Respondents pointed to construction KPIs as difficult to define and open to manipulation (i.e. false reporting) and misinterpretation (e.g. one interviewee cited the example of a questionnaire completed remotely by a tenant compared with one completed in the presence of a 'customer care' manager). The perceived problems of comparing 'like for like' stemmed from the need to contextualise the indicators (e.g. firms may have an artificially high turnover of staff owing to employment of students) and doubts over the way in which the data were collected. Consequently, some organisations used alternative benchmarking frameworks (e.g. the European Foundation Quality Model) to compare their performance with both industry and wider (i.e. non-construction industry) peers.

As for second order comparison, interviews with clients revealed some use of construction KPIs in procurement, though it was restricted to the public sector clients. One social housing group, for instance, based their allocation of work on ratings of 
their contractors derived from the construction KPIs, using performance data for the previous 12 months (although it should be noted that the construction KPIs were used as a second stage in the selection process after the cost of tenders had been considered). A consultant stated that "[construction] KPIs are pretty marginal to the organisation as a whole at the moment, but [they are] very important to team[s...working with]...public and quasi-public clients". Some interviewees had used data from the construction KPIs to demonstrate that client satisfaction figures were ahead of the industry average or that internal targets were based on the national distributions of industry performance as measured through the construction KPIs. For example, one mechanical and electrical contractor reported that repeated measurement of construction KPIs had enabled the firm to demonstrate how the organisation had improved their performance on projects. In contrast, none of the private sector clients interviewed used construction KPIs in procurement. As one architect commented, "we have tried to be more engaged with the private sector but they are not interested in the process". Instead, private sector clients asked for other performance data and one organisation had developed a bespoke system of indicators.

\section{Implications}

The case demonstrates that, as time passed, the objectives of the construction KPIs changed; the indicators themselves broadened and adapted. Such evolution can be expected as experience is gained, initiatives develop that can utilise the data, and policy priorities change. The inclusion of social and environmental sustainability and sub-sector indicators was one such development, reflecting the involvement of different organisations involved in the process. The difficulty of integrating processes that both supported supplier innovation and improved client knowledge also underlies the evolution of construction KPIs and eventually they began to address the needs of construction firms more explicitly (though, as our interviews reveal, not totally successfully), while a separate use of the information by public clients met their needs in a restricted manner. Given government financial support, it was assumed that a cooperative scheme could be developed where clients and construction firms would be happy to work together to share information. However, no industry wide - what we might call 'functional' - benchmarking system emerged within this voluntary process. 
Rather, construction suppliers and clients' representatives gradually allowed the priorities for the scheme as was originally intended to fall down the agenda and the government then gradually removed financial support.

The strategy for any actor - supplier, client or their representatives - is to avoid establishing a policy framework that creates a negative payoff for the organisation (or type of organisation it represents). Policy actors must attempt to create frameworks that benefit those they represent. Frameworks need to guarantee cooperation in the sense of ensuring or incentivizing collaboration between all parties. Dominant strategies should be those that give rise to collaboration. The presence of policies that require one group to follow a dominated strategy cannot work. Without this condition being met, policies clearly fail either at inception or beyond it, or at some later point when incentives are made explicit.

Based on a review of the implementation of the policy and the subsequent outcomes, our conjecture is that no organisation or representative would be willing to accept the rules of a scheme that gave away vital information to another group on a systematic basis or when the information was not thought to be accurate. Therefore, the HighHigh option (bottom right box in Figure 1), the most preferable option for clients as it allows them to make better informed procurement decisions, is not likely to be the preferred option for construction firms. Whether actual assessments of utility or preferences are used, the High-High option is clearly a dominated strategy within the limited game. While a government policy to promote benchmarking within groups might be acceptable (bottom left box in Figure 1), the current design of the construction KPI benchmarking scheme makes this a dominated strategy also. Our interviews highlighted the need for construction firms to have more confidence in the construction KPIs as a basis for making comparisons if the first policy objective of supporting learning was to be met. This suggests that the characteristics of the data underpinning the scheme need to be addressed, especially the voluntary nature of data submission and the absence of independent monitoring and verification of data. Our interviews evidenced that for construction KPIs to meet the second policy 
objective of informing clients, greater involvement was needed by both clients and main contractors (first tier suppliers), potentially as part of a framework for delivering cost, programme and quality improvement. One suggestion from the interviews was that government could standardise the use of construction KPIs on all public sector contracts and make it a contractual obligation to use them. Another was for main contractors to incentivise suppliers within long-term frameworks using the construction KPIs, a way of "aligning commitments along the supply chain". Some interviewees suggested that this could be encouraged by trade associations.

\section{Conclusions}

The foregoing analysis has reviewed the development of the key performance indicators element of UK construction policy. The analysis supports the view that the concept of functional benchmarking involving extensive exchange of information between construction suppliers and their clients and which was promoted in the Egan Report was not capable of implementation. The argument presented here, based on a review of the key policy reports and a series of interviews with construction KPI users, is that such functional benchmarking presents risks to the longer term interests of construction suppliers who seek to avoid involvement when participation is voluntary. In the context of the construction industry, mutual exchange of information is perceived by the construction suppliers and their representatives as likely to undermine their ability to compete on favourable terms.

Our explanation for the outcome of construction KPI policy endorses the important dichotomy outlined by Boxwell (1994) and Wolfram Cox et al (1997); however, while the different forms of benchmarking outlined by these writers are different forms of activity, being carried out in different ways and using different forms of information, and being largely incompatible activities, such a difference between benchmarking activities does not by itself explain why government policy in this area took the course observed. For whilst the initial use of benchmarking may have been consistent with market orientated reforms to influence the behaviour of private sector firms, 
explanation of the development of benchmarking as part of the construction KPIs must, in our view, attend to the question of economic incentives, rather than merely the technicalities of different forms of benchmarking, or lack of political commitment. It is debateable whether the case highlights a failure on the part of government to explicitly consider a priori the expected benefits for industry, or, reflecting the other changes noted above, adaptation of a policy in implementation.

In conclusion, government support for benchmarking activities has strong policy justifications in certain contexts: in the context of organisational learning, government can realistically support the activities of firms when those engaged in innovation face difficulties appropriating the knowledge and know-how they produce; likewise, in the context of information asymmetries in markets, governments can assist decision making by supporting procurers by improving the quality and increasing the quantity of information in existence about what construction firms can deliver; and new public management approaches that employ benchmarking can be used to influence both the public and private sectors in the delivery of services to the public. But attempts to combine these different policies will only succeed if when the limits imposed by the strategic value of information are taken into account. Without this understanding, the only alternative is compulsion. 


\section{Acknowledgements}

We would like to acknowledge the contribution of Dr Kevin Albertson, Dr Dmitri Gagliardi and Professor Colin Talbot for their help in developing this paper. 


\section{References}

Allen, R. C. (1983), Collective Invention. Journal of Economic Behavior and Organization, 4, pp. 1-24.

Anderson, B. \& Peterson, P. G. (1996), The Benchmarking Handbook, (Chapman Hall, London). Binmore, K. (2007), Playing for Real, (Oxford University Press, Oxford).

Binmore, K. \& Klemperer, P. (2002), The biggest auction ever: the sale of the UK 3 G telecom licences. The Economic Journal, 112, 478, pp. 74-86.

Boxwell, R. J. (1994), Benchmarking for Competitive Advantage, (McGraw Hill, New York).

Camp, R. C. (1995), Business Process Benchmarking: Finding and Implementing Best Practices, (ASQC Quality Press, Madison Wisconsin).

Cmd. 4514 (1971), The Organisation and Management of Government R\&D, Papers by Command, (HMSO, London).

Constructing Excellence (2004) Respect for people: a framework for action, available at http://www.constructingexcellence.org.uk/pdf/rfp/rfp_A_Framework for Action.pdf, last accessed October 2012.

Constructing Excellence (2010) UK Industry Performance Report Based on the UK Construction Industry Key Performance Indicators.), available at http://www.constructingexcellence.org.uk/news/pdf_news_articles/KPIv6.pdf, last accessed October 2012.

Courtney, R. (1997), Building Research Establishment: past, present, and future. Building Research and Information, 25, 5, pp. 285-291.

Courtney, R., Rigby, J., Dewick, P. \& Gee, S. (2008), Review of Construction Key Performance Indicators, BERR reference 01.04.07.01/44C ITT No 4, available as an Executive Summary at http://www.bis.gov.uk/analysis/statistics/construction-statistics/keyperformance-indicators, last accessed October 2012.

Cox, A. \& Thompson, I. (1988), On the appropriateness of benchmarking. Journal of General Management, 23, pp. 1-20.

Dattakumar, R. \& Jagadeesh, R. (2003), A review of literature on benchmarking. Benchmarking: An International Journal, 10, 3, pp. 176-209.

Department of Trade and Industry (DTI) (2004) Sustainable Construction Brief 2, available at http://www.bis.gov.uk/files/file13939.pdf, last accessed October 2012.

Egan, J. (1998), Rethinking Construction, The Report of the Construction Task Force., (HMSO, London).

Egan, J. (2002), Accelerating Change, A Report by the Strategic Forum for Construction, (HMSO, London). 
Eleftheriadou, E. \& Mylopoulos, Y. (2008), Game Theoretical Approach to Conflict Resolution in Transboundary Water Resources Management. Journal of Water Resources Planning and Management, 134, 5, pp. 466-473.

Erikson, P. E. (2007), Cooperation and partnering in facilities construction. Facilities, 25, 1, pp. 7-19.

Francis, G. \& Holloway, J. (2007), Themes from the literature on best practice benchmarking: What have we learned? International Journal of Management Reviews, 9, 3, pp. 171189.

Frisvold, G. B. \& Caswell, M. F. (2000), Transboundary water management: game theoretic lessons for projects on the US-Mexico border. Agricultural Economics, 24, pp. 101-111. HM Treasury (2003), The Green Book, London).

Hood, C. (1991), A PUBLIC MANAGEMENT FOR ALL SEASONS. Public Administration, 69, 1, pp. 319.

Jackson, M. (2001), A crash course in implementation theory. Social Choice and Welfare, 18, 4, pp. 655-708.

KPI Working Group (2000), KPI Report for the Minister for Construction: Department of the Environment Transport and the Regions, London, HMSO, available at http://www.bis.gov.uk/files/file16441.pdf, last accessed October 2012.

KPI Zone User Manual (2007), Constructing Excellence and the Department for Business Enterprise and Regulatory Reform.

Latham, M. (1994), Constructing the Team: Final report of the government/industry review of procurement and contractual arrangements in the UK construction industry, (HMSO, London).

Murnighan, J. K. (1994), Game theory and organisational behaviour. Research in Organisational Behaviour, 16, pp. 67-76.

National Audit Office (2001), Modernising Construction, available at http://www.neccontract.com/documents/key\%20reports/NAOModernisingconstructio n.pdf, last accessed October 2012., (HMSO, London).

O'Toole, L. J. (2004), The Theory-Practice Issue in Policy Implementation Research. Public Administration, 82, 2, pp. 309-329.

Spendolini, M. J. (1992), The Benchmarking Book, (AMACOM, New York).

Talbot, C. (2010), Theories of Performance: Organisational and Service Improvement in the Public Domain, (Oxford University Press, Oxford).

von Hippel, E. (1988), The Sources of Innovation. Oxford. 
Wolfram Cox, J. R. W., Mann, L., Samson, D. (1997), Benchmarking As A Mixed Metaphor: Disentangling Assumptions Of Competition And Collaboration. Journal of Management Studies,, 34, 2, pp. 285-314.

Zairi, M. (1998), Benchmarking for Best Practice: Continuous Learning through Sustainable Innovation, (Butterworth Heinemann, Oxford). 